\title{
Anaesthesia in a child with uncorrected aortopulmonary window for non- cardiac surgery
}

\author{
Malavika Kulkarni ${ }^{1^{*}}$, Sushma T K $^{2}$, Avinash Shastry ${ }^{3}$ \\ Associate Professor ${ }^{1 *}$, Assistant Professor ${ }^{2}$, Postgraduate student ${ }^{3}$, Department of Anaesthesia, Kasturba \\ Medical College, Manipal, India.
}

\begin{abstract}
Aortopulmonary window (APW) is a rare congenital cardiac anomaly characterized by communication between ascending aorta and main pulmonary artery. It represents between $0.2 \%$ and $0.3 \%$ of all congenital cardiac lesions. The anaesthetic management of a child with severe pulmonary hypertension associated with right to left shunt is clearly a demanding situation.
\end{abstract}

A13 year old boy presented for open reduction and internal fixation of right femur. The child was diagnosed with congenital heart disease, APW with severe irreversible Pulmonary Artery Hypertension (PAH). Anaesthetic management comprised of a balanced approach with administration of general anaesthesia and regional analgesia with perioperative invasive haemodynamic monitoring.

Keywords: Paediatric; aorto pulmonary window; severe pulmonary artery hypertension; non cardiac surgery

\section{Introduction}

Aortopulmonary window (APW) is a rare condition resulting from incomplete fusion of conotruncal edge and similar in pathophysiology to Patent Ductus Arteriosus but more severe. ${ }^{1}$ Any delay in surgical correction results in severe pulmonary hypertension with the reversal of shunt. Care should to be taken in maintaining the systemic vascular resistance without a rise or drop in pulmonary vascular resistance (PVR)with the reversal of shunt. ${ }^{2}$

\section{Case Report}

A 13 year old boy weighing $28 \mathrm{kgs}$ with a history of slip and fall presented for open reduction and internal fixation of right femur. He was diagnosed with a congenital heart disease five years back on account of poor effort tolerance, frequent respiratory tract infections associated with cough and haemoptysis. ECHO records revealed APW

*Correspondence: Malavika Kulkarni
E mail: malavika.kulkarni@manipal.edu

https://orcid.org/0000-0002-5027-3168

Received: 09/01/2020

Accepted: 15/05/2020

DOI: http:/doi.org/10.4038/slja.v28i2.8532

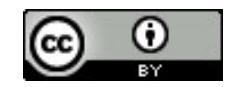

with severe PAH and failed acute vasoreactivity treatment. The child did not show any syndromic features. On evaluation the child was alert, oriented with features of central cyanosis, mild tachypnoea of 22-24/min, $\mathrm{SPO}_{2}-90-92 \%$ on room air and tachycardia of $112 / \mathrm{min}$, BP of $120 / 60 \mathrm{~mm} \mathrm{Hg}$.

Cardiovascular system: Hyperdynamic precordium, S1 normal, S2 loud, with a narrow split. Soft end diastolic murmur in tricuspid area. ECG: sinus rhythm with features of right ventricular hypertrophy. 2D ECHO: Large $18 \mathrm{~mm}$ APW with bidirectional flow, predominantly right to left, dilated right atrium, right ventricle, main pulmonary artery, severe PAH with pulmonary pressure gradient of $56 \mathrm{mmHg}$ and good ventricular systolic function. (Figure 1)

The child was on oral sildenafil $12.5 \mathrm{mg}$ tds and bosentan $15 \mathrm{mg}$ bd. On lab investigations $\mathrm{Hb}$ was $14 \mathrm{~g} \%$. Chest $\mathrm{X}$ ray revealed prominent pulmonary vascular markings. Nil per oral orders were given with continuation of medications. Written informed consent from the parent was obtained. Parents were not agreeable for regional anaesthesia under sedation. Therefore, the plan of anaesthesia was general endotracheal anaesthesia with fascia iliaca block. 
Figure 1: Transthoracic ECHO showing APW in short axis view

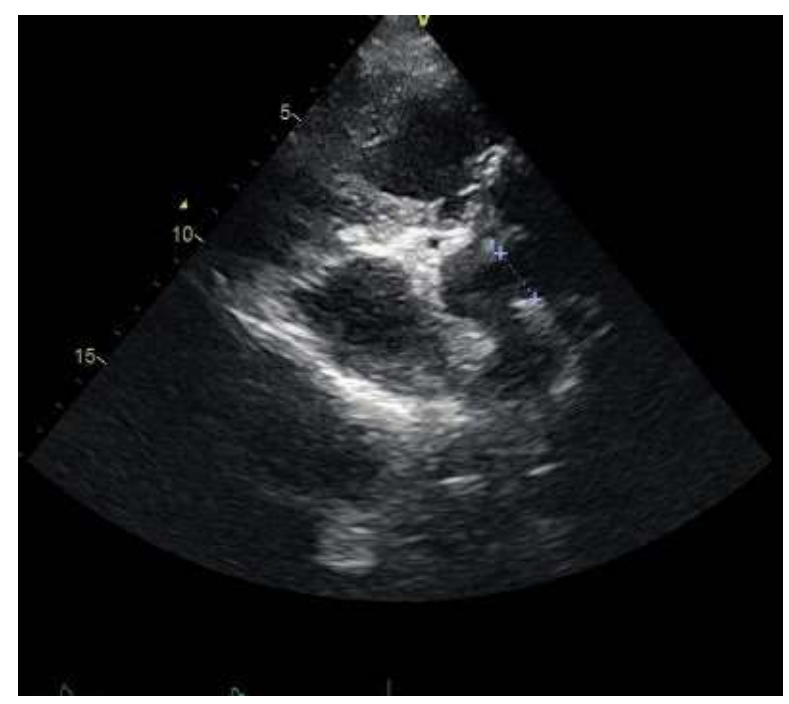

On the day of surgery, child was premedicated with i.v. midazolam $1 \mathrm{mg}$ and fentanyl $60 \mu \mathrm{g}$. Baseline monitors 5 lead ECG, $\mathrm{S}_{\mathrm{P}} \mathrm{O}_{2}$, NIBP were applied. Induction was done with intravenous etomidate $6 \mathrm{mg}$, on confirmation of bag and mask ventilation, vecuronium $3 \mathrm{mg}$ was given. Oral endotracheal intubation was done with $6.5 \mathrm{~mm}$ cuffed tube. Mechanical ventilation was commenced with $\mathrm{O}_{2}$, air and isoflurane at $1.5 \%$. Post induction invasive arterial monitoring from right radial artery, central venous pressure (CVP) monitoring via right internal jugular vein and temperature monitoring was done. Intraoperative multimodal analgesia included an ultrasound guided fascia iliaca block with $20 \mathrm{ml} 0.2 \%$ ropivacaine and i.v. paracetamol $500 \mathrm{mg}$. Intraoperative haemodynamic stability was maintained. Reversal and extubation was done after esmolol $5 \mathrm{mg}$ bolus. Postoperatively pain relief was continued with i.v. fentanyl at 30 microgram per hour. Child was shifted to paediatric intensive care unit for observation and monitoring. Post-operative phase was uneventful.

\section{Discussion}

APW initially results in systemic to pulmonary shunting and when not repaired in time, progresses into development of pulmonary vascular disease. PAH results secondary to vascular remodelling. Persistently elevated pulmonary artery pressure results in right ventricular hypertrophy and dilatation leading to reduction in pulmonary blood flow and cardiac output. Acute rise in PVR can result in reversal of shunt, increased right ventricular wall tension, decreased coronary perfusion followed by ischaemic cardiac arrest. $\mathrm{PAH}$ is a major risk factor for complications such as pulmonary hypertensive crisis (PH crisis), right heart failure and sudden cardiac death. The goals of anaesthetic management for the surgical procedure are to minimize increase in PVR thereby minimising risk of right ventricular ischaemia, prevention of systemic hypotension maintaining haemodynamic stability as close to baseline by providing adequate anaesthesia and analgesia. ${ }^{3,4}$

Both regional and general anaesthesia have been used and hypotension can occur with either of these which needs to be avoided. Close haemodynamic monitoring is extremely important. ${ }^{5}$ Caution is also advised on use of regional techniques that significantly lower SVR and coronary perfusion. ${ }^{5}$

Stressful stimuli during anaesthetic management such as securing intravenous access, endotracheal intubation, mechanical ventilation, emergence and extubation need to be addressed. Maintenance with inhalational agents such as isoflurane at concentrations up to $1 \mathrm{MAC}$ is well tolerated without negative effects on pulmonary pressure or resistance. $^{4,6}$ In our patient in view of good ventricular systolic function and complexity of surgery being intermediate, we did invasive blood pressure and CVP monitoring, intermittent blood gases and an immediate post-operative ECHO. Ventilation was monitored with capnography and pressure-volume and flow loops. Optimal oxygenation with modest hyperventilation (target $\mathrm{PaCO}_{2}$ of $30-35 \mathrm{mmHg}$ ) and avoidance of metabolic acidosis should be adapted with frequent blood gases. ${ }^{6}$ In the presence of persistent hypotension due to increase in PVR, although inotropic agents are necessary, vasoconstrictors seem more valuable.,

\section{Conclusion}

In patients with large APW it is important to be aware of the pathophysiology of cardiac lesion and $\mathrm{PAH}$ in order to plan the anaesthetic management and develop preparedness in handling complications like ventricular failure and acute $\mathrm{PH}$ crisis. 


\section{References}

1. Lake CL, Booker PD. Pediatric cardiac anaesthesia., Lippincott Williams and Wilkins Philadelphia USA; 4th edition 2005: 416-7

2. Junghare SW, Desurkar V. Congenital heart diseases and anaesthesia. Indian J Anaesth. 2017 Sep; 61(9):744-52.

https://doi.org/10.4103/ija.IJA $415 \quad 17$

PMid:28970633 PMCid:PMC5613600

3. Shukla CA, Almodovar C.M. Anaesthetic considerations for children with pulmonary hypertension. PediatrCrit Care Med 2010;11(2)S7073

https://doi.org/10.1097/PCC.0b013e3181c76c6e PMid:20216167

4. Friesen RH, Williams GD. Anesthetic management of children with pulmonary arterial hypertension. PaediatrAnaesth 2008; 18(3):208-16. https://doi.org/10.1111/j.1460-9592.2008.02419.x PMid:18230063

5. Rodrigues JS, Shenoy T, Acharya M. Anesthetic management of a patient with Eisenmenger's syndrome for an emergency caesarean section in an under resourced area. J ObstetAnaesthCrit Care 2015;5:27-9.

https://doi.org/10.4103/2249-4472.155196

6. Nashat H, Kempny A, McCabe C, Price LC, Harries C, Alonso-Gonzalez R, Gatzoulis MA, Wort SJ, Dimopoulos K. Eisenmenger syndrome: Current perspectives. Research reports in clinical cardiology 2017;8:1-12.

https://doi.org/10.2147/RRCC.S117838

7. Gille J, Seyfarth HJ, Gerlach S, Malcharek M, Czeslick E, Sablotzki A. Perioperative anesthesiological management of patients with pulmonary hypertension. Anesthesiol Res Pract. 2012; 2012:356982.

https://doi.org/10.1155/2012/356982

PMid:23097665 PMCid:PMC3477529 